\title{
Comparison of deltamethrin as indoor residual spray or on insecticide treated nets for mosquito control in Lake Chilwa
}

\section{Dylo FPemba $^{1}$, Elizabeth Bandason ${ }^{1}$, Jimmy Namangale ${ }^{2}$}

1. Biology Department, Chancellor College, University of Malawi, Malawi

2. Mathematics Department., Chancellor College, Uniervsity of Malawi, Malawi

Correspondence: D. F Pemba Email: pembadyl@chanco.unima.mw Phone +265 8314283

\begin{abstract}
We conducted a study on the control of mosquitos on Chisi Island in Lake Chilwa from August to November, 2006. The aim was to compare the cost and efficacy of deltamethrin, a pyrethroid based insecticide, when used in insecticide treated nets (ITN) and when used in indoor residual spray (IRS). Thirty village huts were enrolled in the study. Fifteen were systematically selected in a stratified manner and sprayed with deltamethrin following manufacturers' standard application procedures of $0.02 \mathrm{~g} / \mathrm{m}^{2}$. The remaining fifteen were provided with ITNs. In both groups deltamethrin KO tabs were used. Pyrethroid knockdown (PKD) spray was used for indoor rest captures in the houses monthly for three months. Houses treated with IRS had significantly reduced number of mosquitoes resting indoors than houses provided with nets $(p<0.05)$. Based on the prevailing market price of MK550 each, the cost of five nets was calculated as MK2750.00 per house hold of five compared to five $20 \mathrm{~g}$ knock-out tablets costing MK300.00 using IRS. The cost of IRS is 10 times cheaper than ITN. These results suggest that it is cheaper and more effective to use deltamethrin in IRS than in ITN.
\end{abstract}

\section{Introduction}

Indoor residual spraying (IRS) involves the application of insecticides to inside walls or shelter in the areas where the vectors (mosquitos) are strongly endophilic. Insecticides which are used in IRS include cyfuthrin and lambdacyhalothrin. ${ }^{1}$

In practice, the effectiveness of IRS for malaria control depends on the adherence to the specified insecticide application procedure criteria and public acceptance. Deltamethrin is not an environmentally persistent chemical with low toxicity levels in humans, and can be applied by any person with minimal training of less than 15 minutes. The low price, ease of use and availability of $\mathrm{KO}$ tabs distributed for ITN treatment makes deltamethrin accessible for rural populations. However ITNs only provide protection during sleep and requires all members of the household possess a net while IRS can reduce contact with the vector through out the house at any time ${ }^{2}$. ITN reduce malaria by $60 \%{ }^{3}$ however free net distribution does not guarantee the appropriate use and utilization by the most vulnerable members of the households ${ }^{4}$. A combination of ITN and IRS to reduce mosquito-host contact would therefore be an efficient malaria control tool.

Insecticides that have been widely used in IRS are pyrethroids, organophosphates, Dichloro - diphenyl - trichloroethane (DDT). DDT is cheap and of relatively low toxicity to mammals. However the extensive use of DDT and other pyrethroids led to insects developing resistance ${ }^{5}$.

In the use of the insecticide treated nets a number of procedures need to be followed. The nets are impregnated with inexpensive and long lasting pyrethroids. Success of bed nets protection is dependent on the age of the users and the sizes of the nets available 6 . If the ITNs are used properly, at a higher level of coverage, the vector-host contact is reduced because the effect of the insecticide in the net extends even to non users of the net in the same house $e^{4,7}$. For effect of ITNs to extend to non users there is a need of at least 50$60 \%$ ITN coverage in order to achieve community effects ${ }^{8}$.

The transmission rate of malaria is highest in rural areas where purchasing power is the lowest making implementation of ITNs in Malawi challenging. The ownership of the nets is related to the economic status of households. Blue conical nets are sold to distributors at $20 \%$ above direct product cost. Adding the incentive margins for the distributors, the consumers price of the ITNs is equivalent to $\$ 6.00$ (blue conical) $\$ 2.10$ (rectangular). The insecticide kit is sold at a $60 \%$ subsidy.

ITNs require regular re-treatment with insecticide this also poses a problem to the uptake of ITNs. To overcome this Long Lasting Insecticide Treated Nets (LLINTs) that do not require any re-treatment through out their life span have been introduced. The life span of the net itself is another obstacle in the control of malaria, even for LLITNs ${ }^{10}$.

It has been reported that net distribution programs fall short of ensuring that the nets are used, kept appropriately, and the often the most vulnerable members of the households do not benefit from the use of the nets ${ }^{11}$.

Our aim was to analyse the efficacy of deltamethrin $\mathrm{KO}$ tab when used in IRS and in ITNs in rural Malawi and establish the most cost effective yet efficant use of deltamethrin in malaria vector control.

\section{Methods}

\section{Study Area}

The study was conducted in Chisi Island from August to November, 2006. Chisi is one of the islands in Lake Chilwa with a population of over two thousand people ${ }^{12}$.

A total of 30 households were enrolled for the study. Every house was assigned a numerical identification number. Households were randomized and were screened for use of ITNs. 15 were identified for ITN use the other 15 houses for IRS. This was a normal vector control activity by Zomba District Health office in conjunction with Chancellor College. All treatment resources (Deltamethrin and ITNs) were provided by Zomba DHO's office and data collected as a monitoring tool on the efficacy of treatment. Being a routine survey to generate data for monitoring there was no need for 
ethical clearance except for consent by home owners.

Deltamethrin is a $\alpha$-cyano pyrethroid. A $1.6 \mathrm{~g}$ tablet is composed of a freeze-dried suspension concentrate calculated to deliver a target dose of $0.02 \mathrm{~g} / \mathrm{m}^{2}$ for a $16-\mathrm{m}^{2}$ net $^{11}$.

\section{Indoor residual spray}

Deltamethrin KO tabs were used instead of Wettable Powder (WP) or water dispersible granule (WG) formulations because the KO tabs can be easily accessed by rural populations in Malawi. Deltamethrin KO tabs are pre weighed, easy to handle formulation, and are sold in retailers that do not need to be licensed pesticide suppliers. Deltamethrin KO tabs are similar to deltamethrin-K-Othrine WG 250 used in IRS. Bayer's Deltamethrin KO tabs were dissolved in water and sprayed on the inside walls of the house and on the interior parts of the roof to give a required application rate of $0.02 \mathrm{~g} / \mathrm{m}^{2}$. A Hand held 2010 commercial pressure sprayer was used. The spray was applied, typically, at a rate of 4 litres $/ 100 \mathrm{~m}^{2}$ or to a point of run-off. The walls were sprayed evenly in vertical spray pattern, spraying from top to bottom of all internal walls ensuring even coverage.

\section{Insecticide Treated Nets}

Deltamethrin treated nets were distributed to members of the 15 selected households. Deltamethrin was applied at the target dosage of $0.02 \mathrm{~g} / \mathrm{m}^{2}$ on nylon bed nets.

\section{Indoor resting catches}

Study huts were prepared for post treatment indoor catches every fort night there after. The rooms were prepared for knock down sprays (KDS) using a white sheet to cover the floor and all flat surfaces of the remaining furniture whilst ensuring the slightest disturbance of the mosquitoes resting indoors. Aerosol pyrethroid spray was used to knock down mosquitoes. Fifteen minutes after spraying, mosquitoes were collected from the white sheet and counted. Statistical tests used between treatments: Mann-Whitney and test within treatment (monthly comparison): Wilcoxon test.

\section{Results}

On average, the households treated with IRS depicted significantly fewer mean numbers of mosquitoes than those with ITNs allocation (Wilcoxon tests give p-values of less than $5 \%$ in all the three months) (table 1). There were no significant differences between the number of mosquitoes in ITN treatment in each of the three months except the IRS treated in months 1 and 3(Using Wilcoxon tests, except the results from IRS treatments in months 1 and 3,all other p-values are more than $5 \%$ in table 2). A t-test of paired samples (significance 0.05) shows a two tailed test of 0.018 indicating a significant difference between the two treatments. Not all data was collected from the 15 huts because owners were not always available.

\section{Cost Analysis}

Calculations:

Note:
Figure $1 \mathrm{a}$ and $1 \mathrm{~b}$ The mud huts of Chisi Island enrolled in the study.
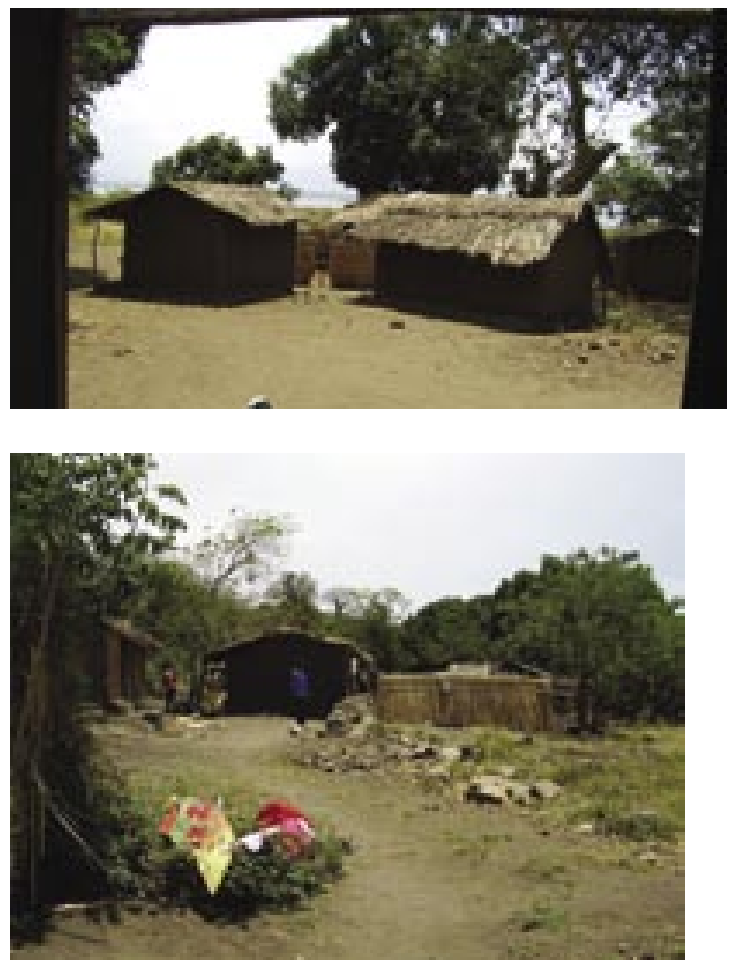

Table1: A comparison of indoor catches between IRS and ITN for three successive months

\begin{tabular}{|l|l|l|l|l|l|}
\hline & Treatment & $\begin{array}{l}\text { Number } \\
\text { of Houses }\end{array}$ & $\begin{array}{l}\text { Mean } \\
\text { Number }\end{array}$ & $\begin{array}{l}\text { Standard } \\
\text { Deviation }\end{array}$ & Wilcoxon Test \\
\hline Month 1 & IRS & 15 & 1.00 & 1.00 & p-value $=0.014$ \\
\hline & ITN & 12 & 3.25 & 2.18 & \\
\hline & & & & & \\
\hline Month 2 & IRS & 15 & 1.73 & 1.03 & p-value $=0.006$ \\
\hline & ITN & 14 & 4.43 & 3.32 & \\
\hline & & & & & \\
\hline Month 3 & IRS & 13 & 2.46 & 1.33 & p-value $=0.044$ \\
\hline & ITN & 13 & 5.92 & 4.29 & \\
\hline
\end{tabular}

Table 2: Comparative Analysis Between ITN and IRS Treatments to Detect Trend.

\begin{tabular}{|l|l|l|l|l|l|l|}
\hline & $\begin{array}{l}\text { IRS1 } \\
\text { vs } \\
\text { IRS2 }\end{array}$ & $\begin{array}{l}\text { IRS1 } \\
\text { vs } \\
\text { IRS3 }\end{array}$ & $\begin{array}{l}\text { IRS2 } \\
\text { vs } \\
\text { IRS2 }\end{array}$ & $\begin{array}{l}\text { ITN1 } \\
\text { Vs } \\
\text { ITN2 }\end{array}$ & $\begin{array}{l}\text { ITN1 } \\
\text { vs } \\
\text { ITN3 }\end{array}$ & $\begin{array}{l}\text { ITN3 } \\
\text { vs } \\
\text { ITN2 }\end{array}$ \\
\hline$p$-value & 0.136 & 0.007 & 0.181 & 0.964 & 0.062 & 0.382 \\
\hline
\end{tabular}

(1) The conical net was used because it is the only one sold at an open market commercial value without any subsidy.

(2) The value of the sprayer was ignored since a common hand held sprayer was used therefore there is no need for the purchase of a specialised sprayers like a Hudson sprayer.

Considering the average household size of 5 individuals ${ }^{14}$ all using treated nets. The cost of a blue conical net and deltamethrin tab at market value was MK850 and MK30 respectively, then:

$5 \times 550.00=2750.00$ per homestead.

$5 \times 50.00=250.00$ per homestead

Total cost of to the household to have treated Nets= 


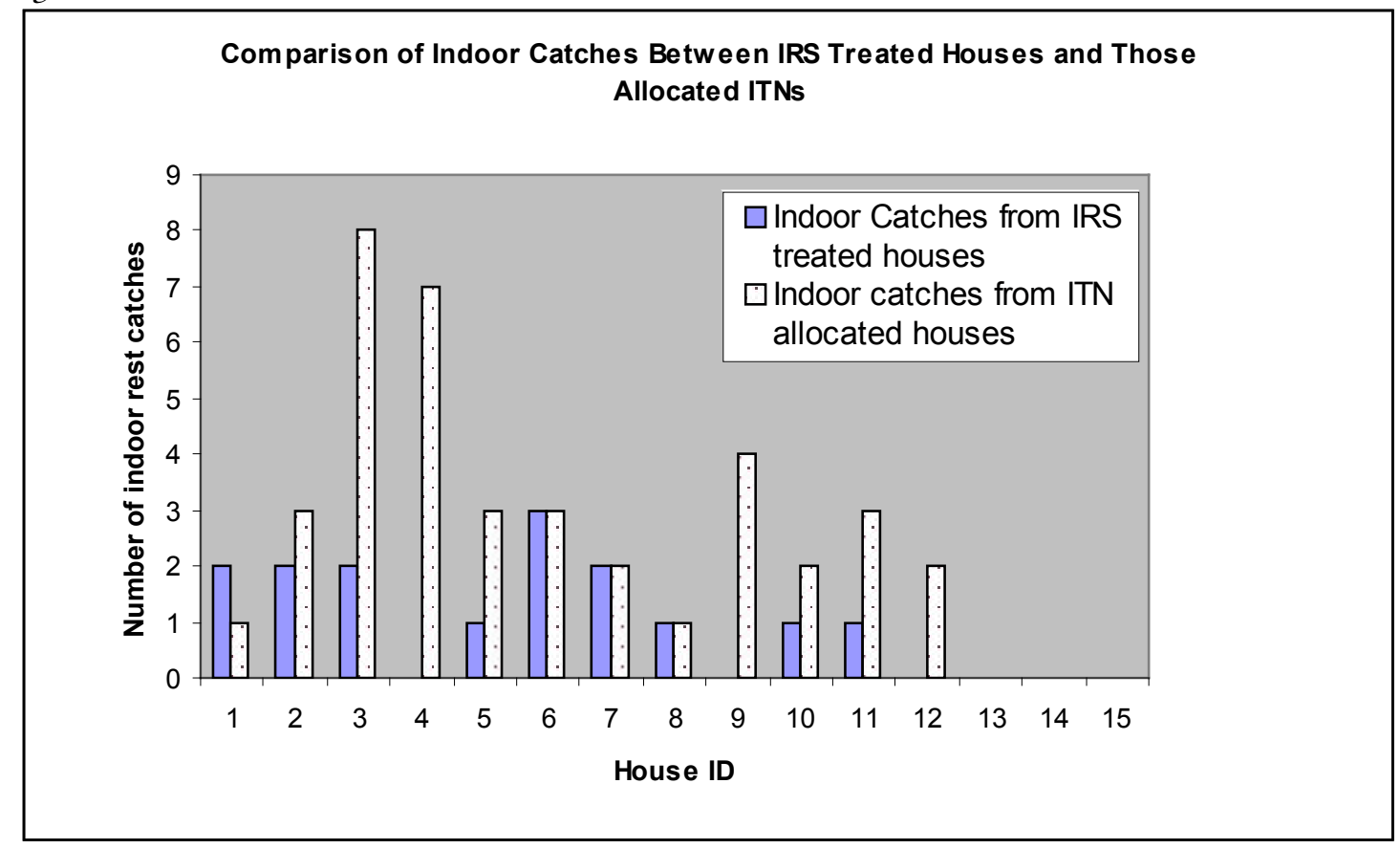

Figure 3 Pyrethroid Knock down Spraying

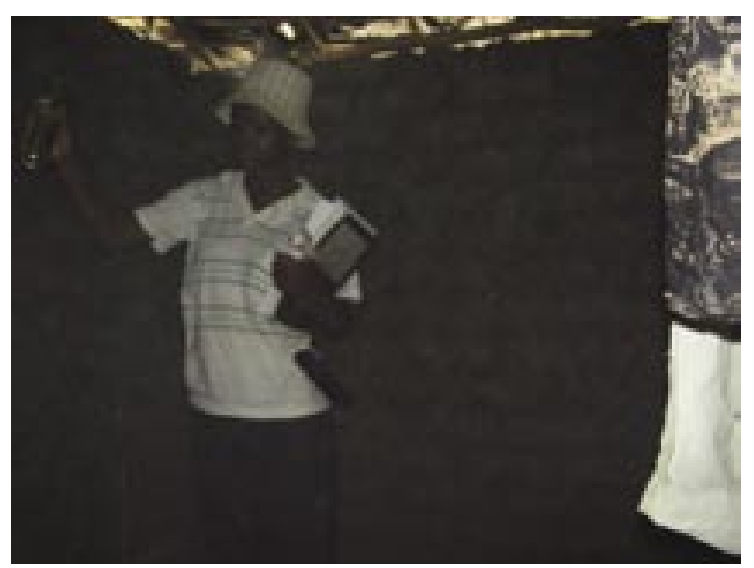

MK3000.00

Cost of IRS using deltamethrin for an average of 2 roomed house typical for 5 individual house hold

Number of deltamethrin tablets required to spray 2 rooms of $2 \mathrm{~m} \times 3 \mathrm{~m} \times 3 \mathrm{~m}: 33 \mathrm{sq} \mathrm{m}$ (include roof area of $3 \mathrm{~m} \times 3 \mathrm{~m}$ )

2 rooms: $33 \times 2=66$

Number of deltamethrin $\mathrm{KO}$ tabs required: $66 \mathrm{~m} \mathrm{sq} / 16 \mathrm{~m} \mathrm{sq}$ $=4$ plus $2 \mathrm{KO}$ tabs for in-house partitions and roof $=6 \mathrm{KO}$ tabs will be required.

Cost for spraying all rooms in the three bed roomed house: MK50 × 6=300.00

Ratio of using ITN to IRS: 10: 1

\section{Discussion}

IRS treatment was significantly better than ITN at reducing number of mosquitoes. No baseline data before intervention was collected which would have allowed comparison with the untreated situation as such indoor rest catches were not employed beyond the household.

The means in table 1 seem to suggest increasing number of mosquitoes on average when we move from month 1 to month 3, and it is not really a significant trend with those treated with ITNs though there seem to have been a
Figure 4 Picking knocked down mosquitoes

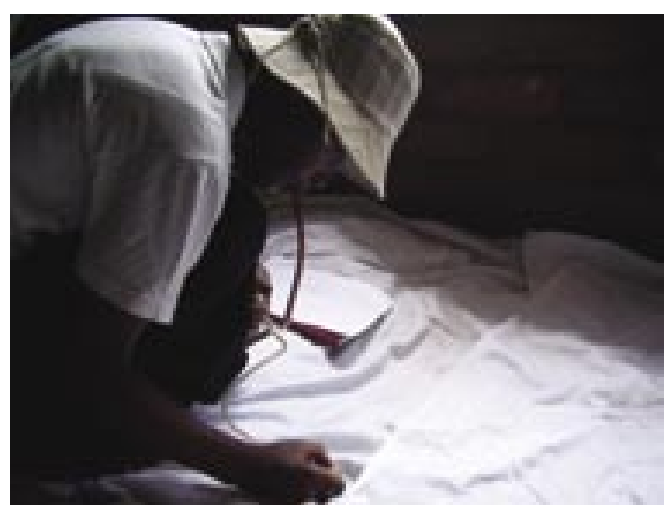

significant increase in IRS treatment between the first and the third month. This is supposedly due to loss of efficacy with time, which can be attributed to the insecticide being affected by the construction materials of the houses. Deltamethrin residual effect is ten to twelve weeks ${ }^{13}$. The t-test result of 0.018 (significance 0.5 ) suggests that the use of deltamethrin in IRS can result in higher efficiency than its use in ITNs. Deltamethrin is more effective in the control of indoor resting mosquitoes as indicated by the reduction in number of indoor resting catches in houses sprayed with deltamethrin(figure 5).

The location of houses did not have an effect on the results as indicated by figure 2 where other effects such as weather, affected the treatments in the same way as reflected by total decreases or increases in catches in both treatments.

\section{Comparison of cost of using Deltamethrin in IRS and in ITNs}

The cost of malaria control through use of nets is higher than for IRS and maybe beyond the purchasing power of a greater proportion of Malawi's population ${ }^{14}$. An average household in the area consists of 5 individuals ${ }^{14}$. We found that the use of deltamethrin in IRS is cheaper than when used in the ITNs for one year. According to the results, for a 
Figure 5:Comparative indoor catches over three months period

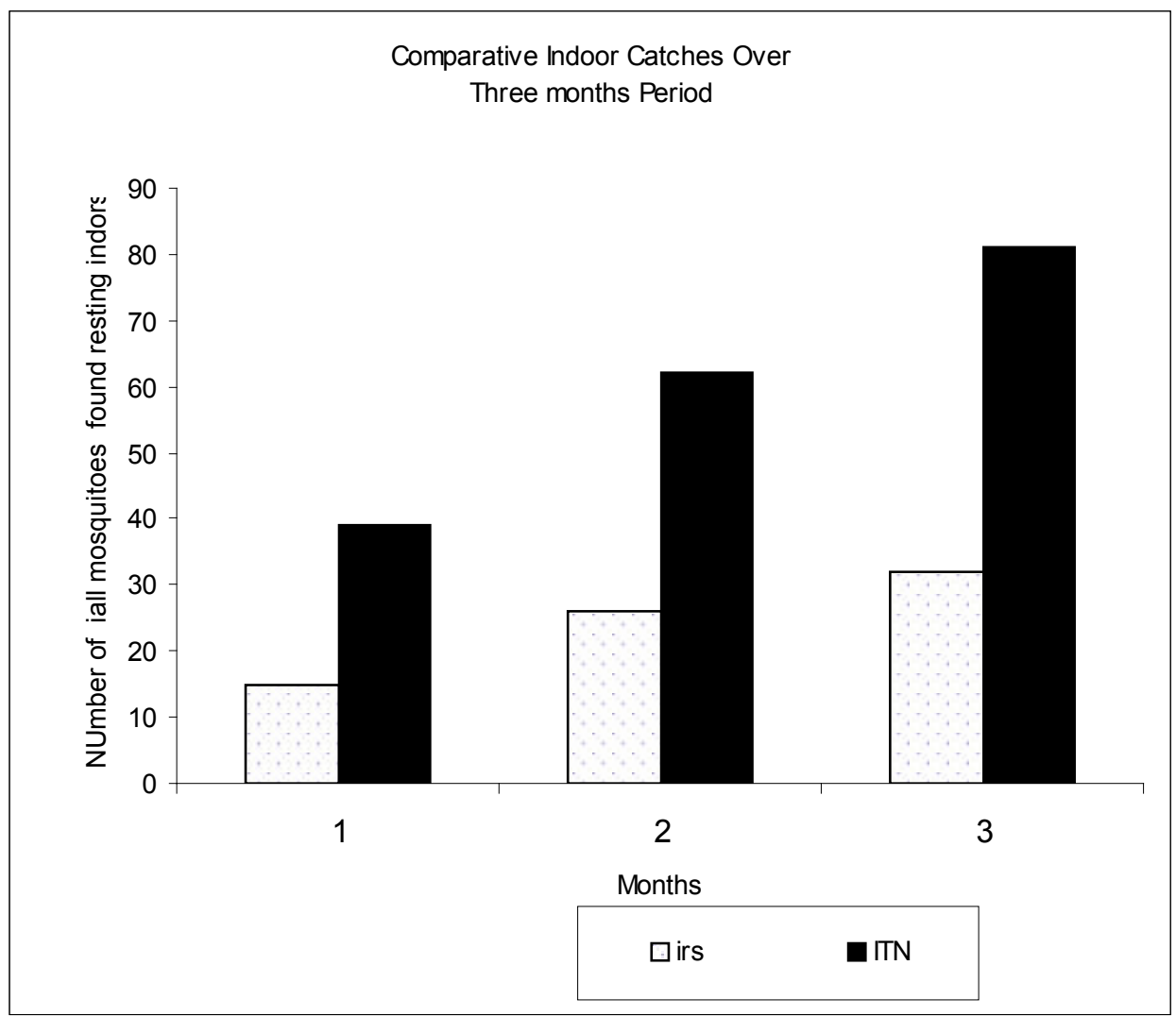

house with five individuals to be protected from malaria they need at least K3000.00 if they use ITNs and the same house with an average number of two rooms needs K300.00 if they use IRS. Use of deltamethrin in IRS is 10 times cheaper than the use of ITNs. It is therefore evident in this case that the use of deltamethrin as in IRS as indicated can be the feasible alternative for malaria control in Malawi and can help in reducing mortality associated with malaria in rural areas.

\section{Conclusion}

Use of deltamethrin in ITNs is costly because the main functioning component is not the net it self but the insecticide the net is impregnated with. It is therefore suitable and economic to use deltamethrin in IRS for malaria control in rural Malawi particularly since a majority of people in rural areas have a low purchasing power.

\section{References}

1. Davis R.S., Robert KD P, Macedo PA : An Ecological Risk Assessment for Insecticides Used in Adult Mosquito Management. Integrated Environmental Assessment and Management. Volume 3, Issue 3 July 2007).

2. Kulkarni MA, Malima R, Mosha FW, Msangi S, Mrema E, Kabula B, Lawrence B, Kinung'hi S, Swilla J, Kisinza W. Efficacy of pyrethroidtreated nets against malaria vectors and nuisance-biting mosquitoes in Tanzania in areas with long-term insecticide-treated net use. Med Vet Entomol. 2007;21(1): 2-21.

3. WHO report Global Malaria Program Surveillance (2002): Impact of long lasting insecticidal treated nets (LLINs) and artemisinin based combination therapies (ACTs) measured using surveillance data, in four African countries

4. Frey C, Traole C, de Allegri M, Kouyate B, Muller O. Compliance of young children with ITN protection in rural Burkina Faso. Malaria Journal (2006) 5: 70

5. Bolland and Williams (2003) Malaria Control during mass movement and disasters (National research council and Programme on forced migration and Health) Joseph Mailman School of Public Health. Columbia University.

6. Moore SJ, Davies CR, Hill N, Cameron MM. Are mosquitoes diverted from repellent-using individuals to non-users? Results of a field study in Bolivia. Trop Med \& Intl Health 2007. 12(4):532-539

7. Lindsay SW, Snow RW, Armstrong JRM, Greenwood BM. Permethrinimpregnated bed nets reduce nuisance arthropods in Gambian houses. Med Vet Entomol. 1989(3)377-383.

8. Lindsay SW, Gibson ME. Bed nets Revisited - Old Idea, New Angle. Parasitol Today. 1988;4:270-272

9. Curtis CF, Control of Malaria Vectors in Africa and Asia.

10. Guillet P, Alnwick D, Cham MK, Neira M, Zaim M, Heymann D. Longlasting treated mosquito nets: a breakthrough in malaria prevention. Bull World Health Organ. 2001;79:998.

11. Winch PJ, Makemba AM, Kamazima SR, Lwihula GK, Lubega P, Minjas JN, Shiff CJ. Seasonal variation in the perceived risk of malaria: implications for the promotion of insecticide-impregnated bed nets. Soc Sci Med. 1994;39:63-75

12. Frey C, Traole C, de Allegri M, Kouyate B, Muller O.Compliance of young children with ITN protection in rural Burkina Faso. Malaria Journal 2006. 5: 70-74

13. Jawar M, Ppinder M, Cham B, Walraven G, Rowley J. Comparison of deltamethrin tablet formulation with liquid deltamethrin and permethrin for bednet treatment in the Gambia. Trop Med Intl Health 2001 6:(4) 309-316.

14. Malawi Demographic Health Survey 2004 